\title{
Current Concepts in Implant Prosthodontics-Materials, Technology, and Occlusion
}

Keywords: Implant restoration; CAD/CAM in implant dentistry; Implant occlusion; Dental implant

\begin{abstract}
Dental implants as a form of replacing missing teeth are being used now more than ever. The success of endosseous implants had led to increased quality of life for these patients. The design of an implant prosthesis is often determined by the position and angulation of the supporting osseointegrated implants. Adequate pre-surgical prosthetic design is essential to the accurate placement of implants for an esthetically acceptable and functional result. Currently, a variety of restorative options are available for the clinician to restore osseointegrated implants in terms of materials used, mode of connection to implants and occlusal schemes. However, the clinical decision regarding which restorative design to use and the choice of material has been a topic of constant debate. This article aims to give the advantages and disadvantages as well as clinical scenarios indicated for different implant restorations.
\end{abstract}

\section{Introduction}

Dental implants as a form of replacing missing teeth are being used now more than ever. The success of endosseous implants had led to increased quality of life for these patients. Since the introduction of dental implants by Bränemark in the 1980's, they have been constantly evolving to fulfill patient needs [1-3].

Since implants are being placed in a younger age group of patients, the service of these implants restorations is expected to be longer. This may require a change in the design of the restoration over the years. Also the possibility to change one restorative option to another provides the possibility of adding more implants to the treatment plan in the future. This can also help the patient to shift from a removable to a fixed restoration [1-4].

The search for successful long-term results has posed several questions concerning the materials used as well as the techniques followed in implant practice. Rapid growth in the fields of dental technology and biomaterials has increased the dilemmas of the clinician regarding the choice of material and design of the implant restoration. The connection between the implant to the restorative component is an essential factor to consider while designing the definitive restoration [5]. The factors that influence different methods of fixation of the prostheses to the implants are:

1. Method of restorative connection, i.e. cement-retained versus screw-retained;

2. Passivity of the framework, i.e. cast versus milled restorations;

3. Porcelain fused to metal (PFM) versus computer-aided design/computer-aided manufacturing (CAD/CAM) milled and zirconia restorations;

\section{Eournal of Oral Biology}

Agnetha Valladares*, Alessandro Grisa, Arshin Hotchandani, Kirkor Cinarli and Mary Kang

Department of Periodontology and Implant Dentistry, New York University, USA

\section{*Address for Correspondence}

Agnetha Valladares, Department of Periodontology and Implant Dentistry, New York University, Clinic 5W, 345 E 24th St, New York, NY 10010, USA, Tel: +1-917-854-7300; E-mail: av1836@nyu.edu

Submission: 14 January, 2018

Accepted: 12 February, 2018

Published: 20 February, 2018

Copyright: ๑ 2018 Valladares A, et al. This is an open access article distributed under the Creative Commons Attribution License, which permits unrestricted use, distribution, and reproduction in any medium, provided the original work is properly cited.

\section{Meso-structures;}

5. Occlusion;

6. Future trends.

The purpose of this article is to review and discuss different implant prosthodontic options currently available to the clinician to restore dental implants.

\section{Materials and Methods}

A search of the literature was performed focusing on implant prosthodontics, materials used for fabrication and occlusal schemes. Clinical data in this study was obtained from the anonymous Implant database (ID) at the Ashman Department of Periodontology and Implant Dentistry at the New York University College of Dentistry. This data was extracted as de-identified information from routine treatment of patients. The ID was certified by the Health Insurance Portability and Accountability Act (HIPAA) and approved by the University Committee on the Activities Involving Human Subjects (UCAIHS). A computer search of electronic database from MEDLINE and PubMed at the Waldman Library at the NYUCD was performed. Keywords such as "dental implant", "implant restoration", "implant occlusion", "CAD/CAM restoration", "meso-structure", "screwretained" and "cement-retained" were used, alone and in combination, to search the databases. Non-English language publications were excluded. The search was limited to studies involving human subjects. There were no restrictions regarding the type of study design.

\section{Results}

The results of this review are based on clinical findings and literature review. These are assimilated to help the clinician for designing the implant supported restoration and occlusal scheme as shown in Table 1.

\section{Cement-retained versus screw-retained restorations}

Restoration of osseointegrated dental implants can include a screw-retained or cement-retained prosthesis, or both [5]. This has always been a discussion between practitioners as to which one is 
Citation: Valladares A, Grisa A, Hotchandani A, Cinarli K, Kang M. Current Concepts in Implant Prosthodontics-Materials, Technology, and Occlusion. J Oral Biol. 2018; 5(1): 5.

better. The option seems to be predominantly based on the clinician's preference although both selections have individual advantages and limitations [6]. Numerous authors have highlighted the relevance of fabricating a cement-retained prosthesis due to its versatility in esthetic, technique simplicity and most of all, easier passivity of fit for single or multiple implants [7]. Figures 1A-1C illustrate how a cementretained restoration for the maxillary arch can be used to fulfil the esthetic demands of the patient by avoiding screw access holes on the buccal aspect of the restoration. An added advantage of luting agents is the gasketing of spaces between components, which excludes food debris and microbes which degrade and produce toxins (revealed by the smell of putrefying material when unsealed implant components are disassembled). To make cement-retained restorations retrievable, provisional cements are commonly used [8]. However, breaking of the cement seal does not always come easily, resulting in a damaged restoration. In addition, excess cement which has been associated with the progression of peri-implant disease such as peri-mucositis and peri-implantitis has been a major dilemma [9]. Throughout the life span of an implant prosthesis, the clinician may be required to remove the restoration for hygiene, repair, and abutment screw tightening procedures, and a screw-retained design makes all of these procedures possible [10]. In a screw-retained prosthesis, the screw delivers a solid joint between the implant abutment and restoration, allowing all the benefits of successful retrievability for maintenance, and therefore, eliminating the need for cement (Figures 2A-2C) [5].

\section{Cast restorations versus milled restorations}

Passive fit of the implant restoration is assumed to be one of the most important factors for the maintenance of the bone-implant interface. A passive fitting framework should not induce any strain on the supporting components and the crestal bone. Biomechanical complications are encountered due to misfits at the implant abutment interface. These misfits lead to straining of the crestal bone and consequently micro fractures or remodeling, which can cause implant failures [11-13]. To limit mechanical and biologic complications,
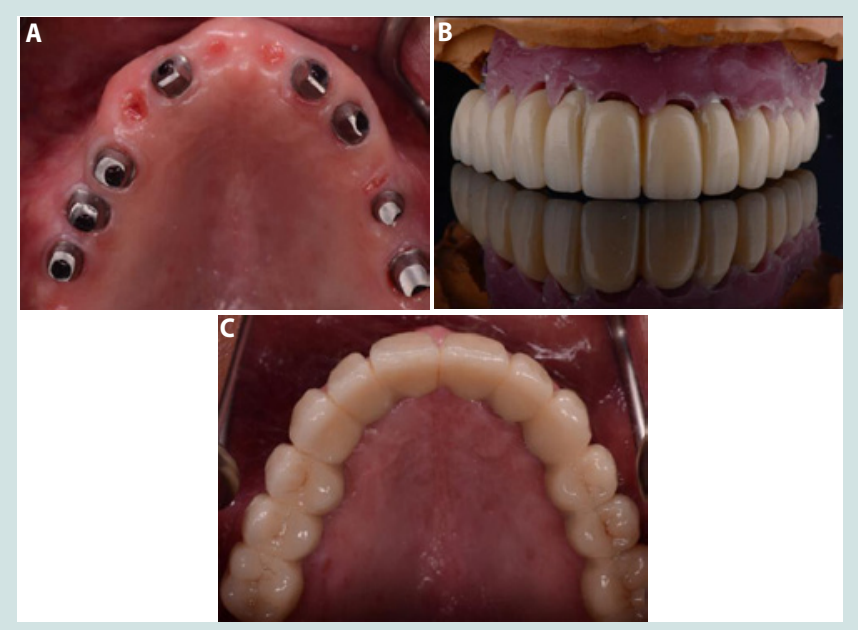

Figure 1: A: Maxillary implants with milled custom abutments for full arch cement-retained zirconia restoration. B: Full arch CAD/CAM milled zirconia framework with layered feldspathic ceramic. C: Delivery of cement-retained maxillary full arch zirconia restoration. recent reports have recommended misfit limits of $50 \mu \mathrm{m}$ and even less than $25 \mu \mathrm{m}$ [14]. Traditionally, implant supported fixed prosthesis frameworks have been cast by means of the lost wax technique to cast and then braze to obtain one-piece, full arch metal frameworks. Imprecision can occur making it difficult to obtain a passive fit. The lack of passive fit may cause micro movement. This is clinically seen as loss of cement-implant attachment or screw loosening of the prosthesis. To overcome these issues associated with casting, laser welding was introduced. The full-arch metal frame is segmented, and the individual segments are then welded with the help of a laser to achieve a precise passive fit [15]. Paniz G et al. compared the fit of cast and milled full arch framework fabricated in vitro from titanium and cobalt-chromium [14]. They noticed that milled frameworks made of titanium or cobalt-chromium was more accurate as compared to cast ones. Also, the milled titanium frameworks weighed less than the cobalt-chromium and the cast frameworks [14]. Currently the most promising results for full arch restorations have been obtained with laser scanned and CAD/CAM milled titanium and zirconia frameworks. The often-encountered misfit of cast restorations is no longer clinically acceptable (Figures 3A-3F) [16].

\section{Porcelain fused to metal restorations versus CAD/CAM restorations}

CAD/CAM technology has been used to fabricate implant restorations and abutments using titanium and its alloys and ceramics such as aluminum oxide or zirconium oxide. The high strength of these materials has increased the longevity of such restorations and their clinical applications. With the help of this technology, the entire work flow from planning to restoration can be virtually done to achieve the final desired esthetics and functional success of implant restorations. CAD/CAM restorations are milled from a solid block of material which makes them more homogenous. This increases their mechanical properties. Also, the inaccuracies encountered during waxing, investing and casting of a restoration are avoided. CAD/ CAM ceramic abutments also provide the optimal optical properties of a natural tooth and superior soft tissue response [17].

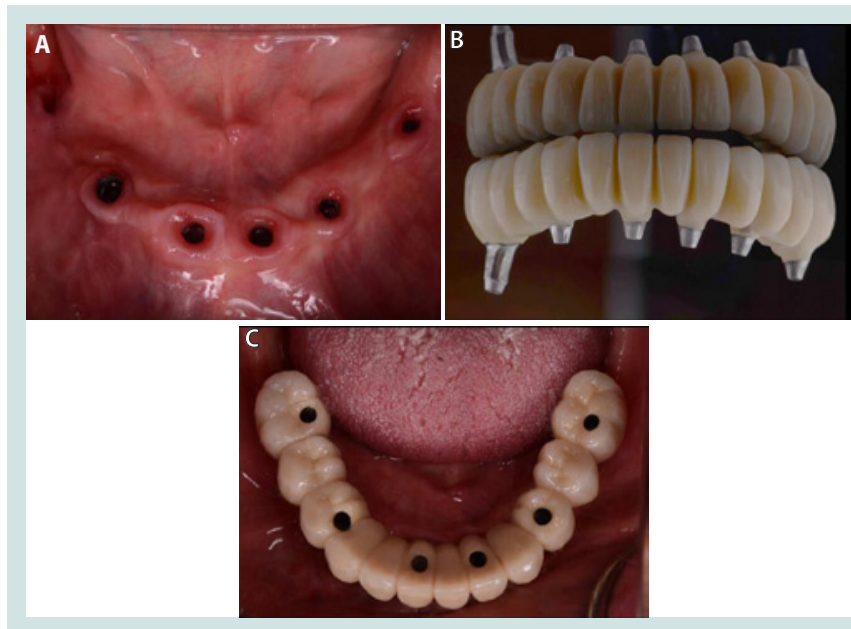

Figure 2: A: Mandibular implants placed in strategic locations for full arch restoration. B: Porcelain fused to metal (PFM) screw-retained mandibular full arch restoration. C: Delivery of screw-retained mandibular full arch PFM restoration. 
Citation: Valladares A, Grisa A, Hotchandani A, Cinarli K, Kang M. Current Concepts in Implant Prosthodontics-Materials, Technology, and Occlusion. J Oral Biol. 2018; 5(1): 5

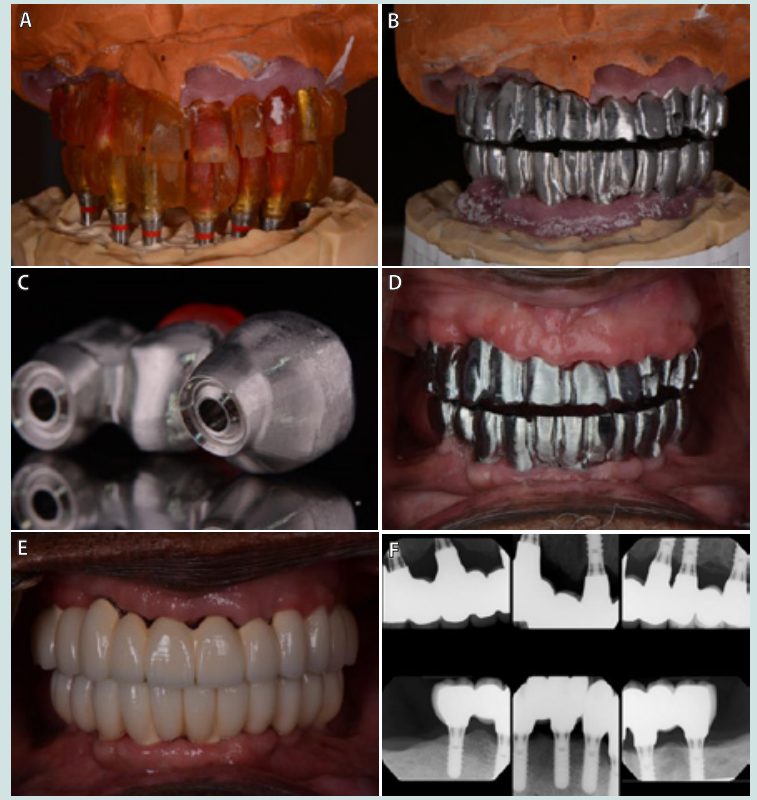

Figure 3: A: Prototype of the definitive restoration made of pattern resin which is scanned for milling of the final restoration. B: CAD/CAM milled final restoration which is a replica of the prototype. C: Precise milling of the restoration helps achieve intimate fit to the implant platform in a passive manner. D: Try in of the milled metal framework intraorally. E: Delivery of the definitive PFM restoration. F: Accurate fit of the milled PFM restoration verified using radiographs.

Zirconium oxide, known as zirconia, possesses good chemical and physical properties [18]. Zirconia stabilized with yttrium oxide results in high flexural strength and fracture toughness owing to a process known as transformation toughening [18-21]. Zirconium oxide also has low corrosion potential and low thermal conductivity [18-21]. In addition to this, the biocompatibility of zirconia reduces the adherence of bacteria and their products on its surface [18-21]. Most zirconia-based restorative systems use computer-aided design/ computer-aided manufacturing (CAD/CAM) technology for the design and the fabrication of the zirconia frameworks. Better esthetics are achieved with zirconia restorations due to the natural shade of the underlying framework which helps eliminate the grey effect with metal substrates. Zirconia layered with feldspathic porcelain have shown failures and cracking of the veneer porcelain due to stress concentration in the zirconia framework. To avoid this, full-arch implant cases should be recorded with an accurate impression using a rigid impression material. Additional steps such as fabrication of a verification jig and full-contour acrylic pattern resin can be used to verify the passivity and fit of the restoration before finally milling the restoration. Other factors such as occlusion, design of the prosthesis and firing protocols are also important to overcome the chipping of veneering porcelain (Figures 4A-4G) [22,23].

\section{Clinical significance of meso-structures in implant restorations}

The position and angulation of the implants oftentimes determines the design of the implant prosthesis. The inaccurate position of implants may result in compromising the esthetics, phonetics, and function. To compensate for the mis-angulated implant during the prosthetic phase of treatment, most common methods have been to use an angulated or custom abutment [24-26]. If the implants are placed at extremely varied angles, the screw-hole will be positioned in the buccal surface which is an unesthetic result. For full arch restorations, the meso-structure, which is a connection between the abutment and underneath the definitive restoration, can be used to correct the unfavorable angulations while still maintaining the restoration as screw-retained and retrievable.

Meso-structure allows for a stable prosthetic base and helps mask the unfavorable access openings. Additionally, it splints the abutments and provides a more precise fit of components. It also allows for better distribution of the occlusal loads, improving longterm prognosis (Figures 5A-5C and 6A-6G) [27].

\section{Occlusal considerations for implant restorations}

Dental implants, unlike natural teeth, are ankylosed to the adjacent bone. The absence of periodontal ligament with mechanoreceptors around dental implants gives them no proprioceptive sensation or shock-absorbing action. To predictably achieve longevity of implant restorations, the occlusal forces should be biomechanically controlled

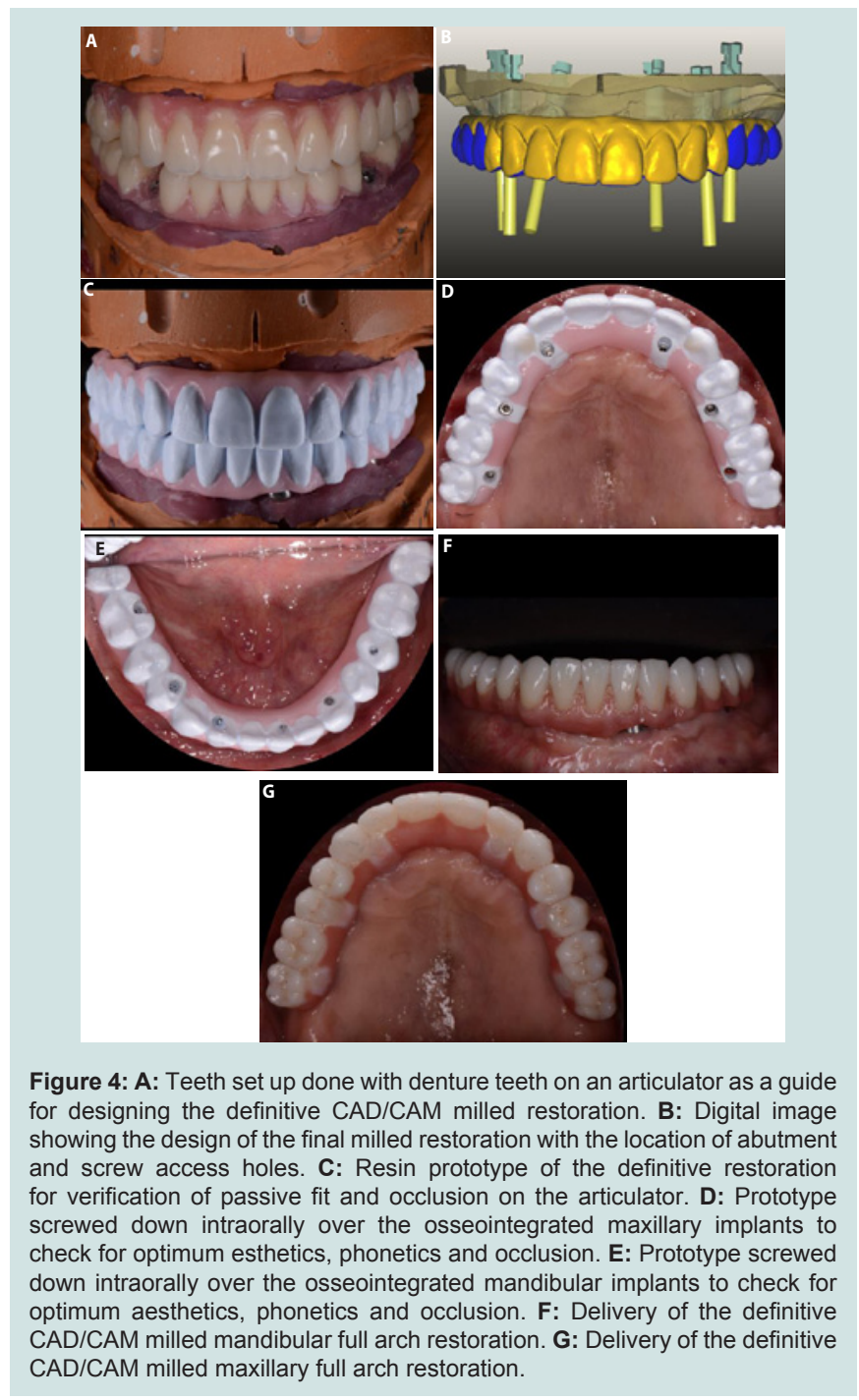


Citation: Valladares A, Grisa A, Hotchandani A, Cinarli K, Kang M. Current Concepts in Implant Prosthodontics-Materials, Technology, and Occlusion. J Oral Biol. 2018; 5(1): 5.

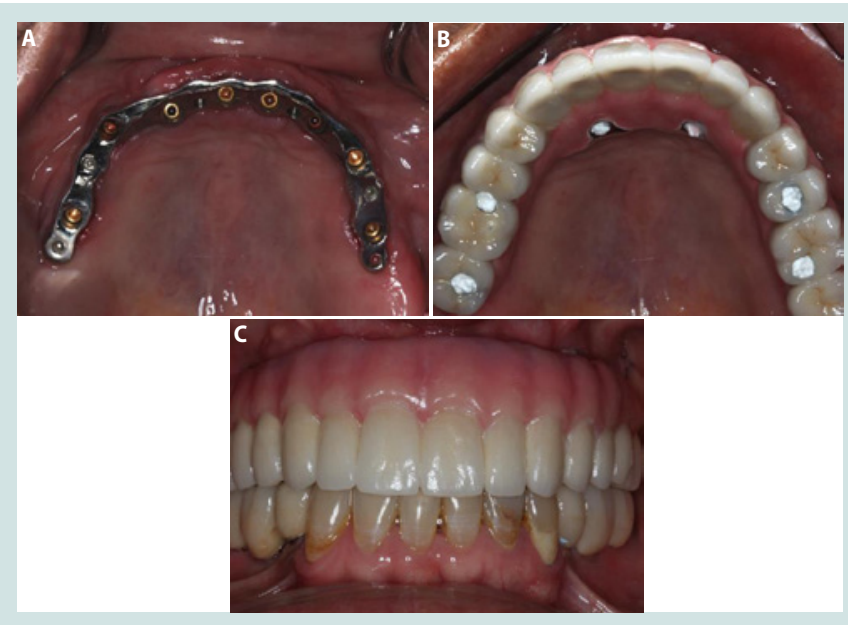

Figure 5: A: Meso-structure used to splint the osseointegrated implants and deliver a full arch screw-retained restoration. B: Delivery of the final PFM full arch restoration supported by the meso-structure with the screw access holes emerging on the lingual and occlusal aspect of the restoration. C: Frontal retracted view of the definitive PFM restoration.
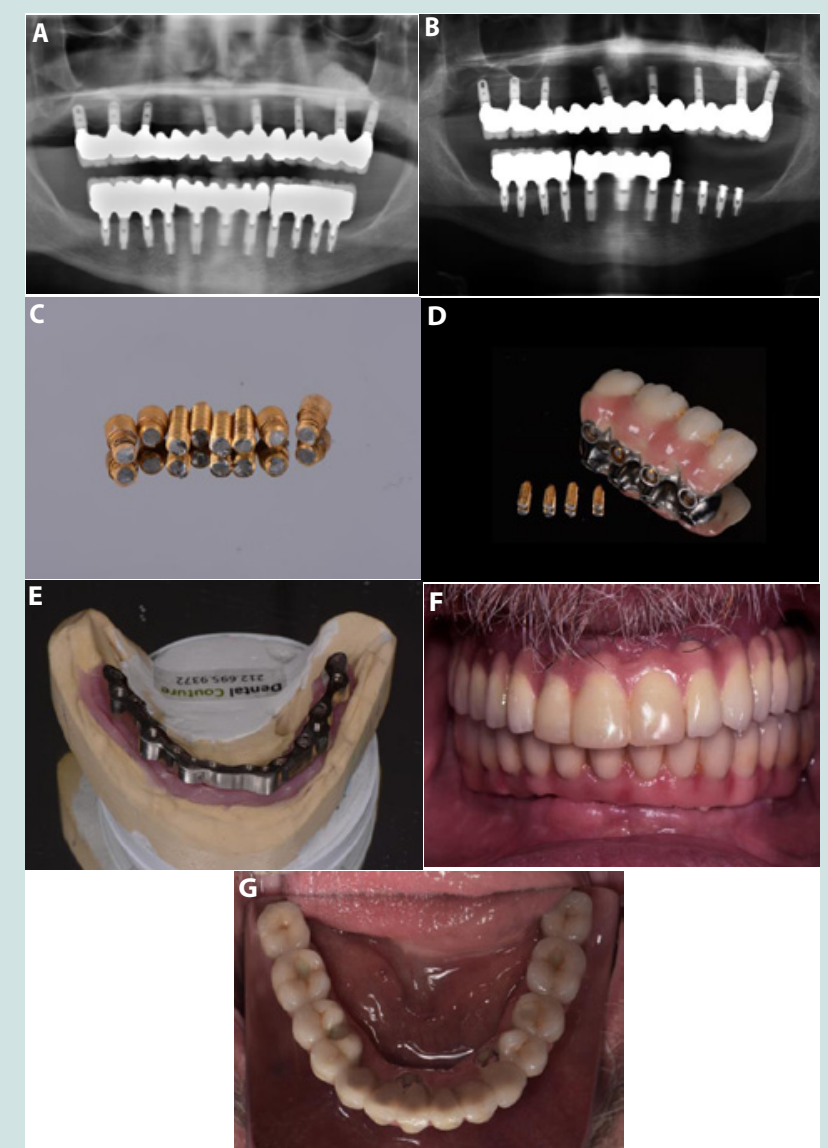

Figure 6: A: Panoramic radiograph showing the segmented mandibular full arch restoration. B: Panoramic radiographic showing recurrent abutment screw fractures that were encountered with the restoration. C: Retrieved abutment screws from the implants. D: Fractured restoration with the abutment screws. E: Meso-structure milled to overcome the repeated fracture of the abutment screws in the mandibular full arch restoration. F: Frontal retracted view of the definitive mandibular restoration delivered over an underlying meso-structure. G: Occlusal view of the definitive restoration. to avoid mechanical breakdown of the prosthesis and crestal bone loss [28].

For single tooth implant restoration, anterior and lateral guidance should be planned on remaining natural teeth. Working and nonworking contacts should be avoided on the restorations. While occluding the teeth, light contacts at a heavy bite and no contact at a light biting force in maximum intercuspation are recommended to distribute the occlusal forces on teeth and implants $[29,30]$.

Bilateral balanced occlusion has been used in cases of full-arch implant restorations opposing a complete denture. For situations with opposing natural dentition, group-function has been the choice of occlusal scheme. Alternatively, mutually protected occlusion with a shallow anterior guidance can also be used [31-33]. We found that canine guidance occlusion increased the risk of screw joint failure at the canine site due to stress concentration on that area [34]. When a cantilever is utilized in a full-arch fixed implant prosthesis, infraocclusion $(100 \mu \mathrm{m})$ on a cantilever unit was suggested to reduce mechanical failure of the restoration $[35,36]$.

For an implant retained and supported overdenture, bilateral balanced occlusion with a lingualized occlusal scheme has been recommended on well-formed normal ridges. Monoplane occlusion should be considered for the extremely resorbed ridges $[33,37,38]$.

When planning for occlusal scheme for implant restorations, the clinician must consider the existing occlusal condition of the patient. While designing the final restoration, the clinician should plan for future scheme of occlusion when moving from partial to full-arch restoration or from removable to fixed restorations.

\section{Future Trends}

Digital dentistry has brought a new wave of technology in implant restorations. It has revolutionized the way we acquire information, devise treatment plans, perform surgery and fabricate restorations. New processes allow us to consider completely new ways of approaching implant treatment. The quality of the restorations has improved with the introduction of standardized production processes. This in turn enhances the productivity of dental professionals and laboratories. It has made it possible to machine new materials like high performance ceramics and titanium with high accuracy.

Benefits of digital work flows include reduced clinical time, simplified technical production, higher quality, and precision of implant prosthetic reconstruction [39-42]. Moreover, timeconsuming and complex steps in fabrication can be shortened, expensive manpower resources reduced and patient discomfort avoided.

However, many drawbacks are also associated with digitalization. These include high initial cost of investment and maintenance, multiple updates required with software and hardware, software compatibility issues, and adaptation to constantly evolving new materials. Also, a steep learning curve for the clinician may be involved as experience and technical knowledge are essential for success [39-42].

\section{References}

1. Brånemark PI, Hansson BO, Adell R, Breine U, Lindström J, et al. (1977) Osseointegrated implants in the treatment of edentulous jaw. Experience from a 10-year period. Scand J Plast Reconstr Surg 16: 1-132. 
Citation: Valladares A, Grisa A, Hotchandani A, Cinarli K, Kang M. Current Concepts in Implant Prosthodontics-Materials, Technology, and Occlusion. J Oral Biol. 2018; 5(1): 5.

2. Adell R, Lekholm U, Rockler BR, Brånemark PI (1981) A 15-year study of osseointegrated implants in the treatment of the edentulous jaw. Int $\mathrm{J}$ Oral Surg 10: 387-416.

3. Adell R, Eriksson B, Lekholm U, Brånemark PI, Jemt T (1990) Long-term follow-up study of osseointegrated implants in the treatment of totally edentulous jaws. Int J Oral Maxillofac Implants 5: 347-359.

4. Bryant SR, Zarb GA (1998) Osseointegration of oral implants in older and younger adults. Int J Oral Maxillofac Implants 13: 492-499.

5. Hebel KS, Gajjar RC (1997) Cement-retained versus screw-retained implant restorations: achieving optimal occlusion and esthetics in implant dentistry. $J$ Prosthet Dent 77: 28-35.

6. Taylor TD, Agar JR, Vogiatzi T (2000) Implant prosthodontics: current perspective and future directions. Int J Oral Maxillofac Implants 15: 66-75.

7. Andersson B, Ödman P, Lindvall AM, Brånemark PI (1998) Cemented single crowns on osseointegrated implants after 5 years: results from a prospective study on CeraOne. Int J Prosthodont 11: 212-218.

8. Breeding LC, Dixon DL, Bogacki MT, Tietge JD (1992) Use of luting agents with an implant system: part I. J Prosthet Dent 68: 737-741.

9. Wilson TG Jr (2009) The positive relationship between excess cement and peri-implant disease: a prospective clinical endoscopic study. J Periodontol 80: $1388-1392$

10. Sones AD (1989) Complications with osseointegrated implants. J Prosthe Dent 62: 581-585.

11. Sahin S, Çehreli MC (2001) The significance of passive framework fit in implant prosthodontics: current status. Implant Dent 10: 85-92.

12. Jemt T (1991) Failures and complications in 391 consecutively inserted fixed prostheses supported by Brånemark implants in edentulous jaws: a study of treatment from the time of prosthesis placement to the first annual checkup. Int J Oral Maxillofac Implants 6: 270-276.

13. Pietrabissa R, Contro R, Quaglini V, Soncini M, Gionso L, et al. (2000) Experimental and computational approach for the evaluation of the biomechanical effects of dental bridge misfit. J Biomech 33: 1489-1495.

14. Paniz G, Stellini E, Meneghello R, Cerardi A, Gobbato EA, et al. (2013) The precision of fit of cast and milled full-arch implant-supported restorations. Int J Oral Maxillofac Implants 28: 687-693.

15. de Sousa SA, de Arruda Nobilo MA, Henriques GE, Mesquita MF (2008) Passive fit of frameworks in titanium and palladium-silver alloy submitted the laser welding. J Oral Rehabil 35: 123-127.

16. Katsoulis J, Mericske Stern R, Rotkina L, Zbären C, Enkling N, et al. (2014) Precision of fit of implant supported screw-retained 10-unit computeraided-designed and computer-aided-manufactured frameworks made from zirconium dioxide and titanium: an in vitro study. Clin Oral Implants Res 25 $165-174$

17. Fuster-Torres MA, Albalat-Estela S, Alcañiz-Raya M, Peñarrocha-Diago $M$ (2009) CAD/CAM dental systems in implant dentistry: update. Med Oral Pato Oral Cir Bucal 14: E141-E145.

18. Piconi C, Maccauro G (1999) Zirconia as a ceramic biomaterial. Biomaterials 20: $1-25$

19. Manicone PF, Rossi lommetti P, Raffaelli L (2007) An overview of zirconia ceramics: basic properties and clinical applications. J Dent 35: 819-826.

20. Wang $\mathrm{H}$, Aboushelib MN, Feilzer AJ (2008) Strength influencing variables on CAD/CAM zirconia frameworks. Dent Mater 24: 633-638.

21. Raigrodski AJ, Chiche GJ, Potiket N, Hochstedler JL, Mohamed SE, et al. (2006) The efficacy of posterior three-unit zirconium-oxide-based ceramic fixed partial dental prostheses: a prospective clinical pilot study. J Prosthet Dent 96: 237-244.

22. Kapos T, Ashy LM, Gallucci GO, Weber HP, Wismeijer D (2009) Computeraided design and computer-assisted manufacturing in prosthetic implant dentistry. Int J Oral Maxillofac Implants 24 Suppl: 110-117.
23. Papaspyridakos $P$, Lal K (2008) Complete arch implant rehabilitation using subtractive rapid prototyping and porcelain fused to zirconia prosthesis: a clinical report. J Prosthet Dent 100: 165-172.

24. Balshi TJ, Ekfeldt A, Stenberg T, Vrielinck L (1997) Three-year evaluation of Brånemark implants connected to angulated abutments. Int J Oral Maxillofac Implants 12: 52-58.

25. Sethi A, Kaus T, Sochor P, Axmann-Krcmar D, Chanavaz M (2002) Evolution of the concept of angulated abutments in implant dentistry: 14-year clinical data. Implant Dent 11: 41-51.

26. Lima Verde MA, Morgano SM, Hashem A (1994) Technique to restore unfavorably inclined implants. J Prosthet Dent 71: 359-363.

27. Lee JH, Frias V, Woo C, Maiberg R (2007) Fixed prosthesis with a milled bar for correcting misangled implants: a clinical report. J Prosthet Dent 97: 129-132.

28. Schulte W (1995) Implants and the periodontium. Int Dent J 45: 16-26.

29. Lundgren D, Laurell $L$ (1994) Biomechanical aspects of fixed bridgework supported by natural teeth and endosseous implants. Periodontol 2000 4: 23-40.

30. Misch CE (1993) Occlusal considerations for implant supported prostheses. Contemp Implant Dent: 705-733.

31. Chapman RJ (1989) Principles of occlusion for implant prostheses: guidelines for position, timing, and force of occlusal contacts. Quintessence Int 20: 473480 .

32. Hobo S, Ichida E, Garcia LT (1989) Ideal occlusion. Osseointegration Occlusal Rehabil: 315-328.

33. Wismeijer D, van Waas MA, Kalk W (1995) Factors to consider in selecting an occlusal concept for patients with implants in the edentulous mandible. J Prosthet Dent 74: 380-384.

34. Wie H (1995) Registration of localization, occlusion and occluding materials for failing screw joints in the Brånemark implant system. Clin Oral Implants Res 6: 47-53.

35. Lundgren D, Falk H, Laurell L (1989) Influence of number and distribution of occlusal cantilever contacts on closing and chewing forces in dentitions with implant-supported fixed prostheses occluding with complete dentures. Int J Oral Maxillofac Implants 4: 277-283.

36. Falk H, Laurell L, Lundgren D (1990) Occlusal interferences and cantilever joint stress in implant-supported prostheses occluding with complete dentures. Int J Oral Maxillofac Implants 5: 70-77.

37. Lang BR, Razzoog ME (1992) Lingualized integration: tooth molds and an occlusal scheme for edentulous implant patients. Implant Dent 1: 204-211.

38. Mericske Stern RD, Taylor TD, Belser U (2000) Management of the edentulous patient. Clin Oral Implants Res 11 Suppl 1: 108-125.

39. Beuer F, Schweiger J, Edelhoff D (2008) Digital dentistry: an overview of recent developments for CAD/CAM generated restorations. Br Dent J 204: 505-511.

40. Christensen GJ (2009) Impressions are changing: deciding on conventional, digital or digital plus in-office milling. J Am Dent Assoc 140: 1301-1304.

41. Joda T, Brägger U (2015) Time-efficiency analysis comparing digital and conventional workflows for implant crowns: A prospective clinical crossover trial. Int J Oral Maxillofac Implants 30: 1047-1053.

42. Gallucci GO, Avrampou M, Taylor JC, Elpers J, Thalji G, et al. (2016) Maxillary implant-supported fixed prosthesis: a survey of reviews and key variables for treatment planning. Int J Oral Maxillofac Implants. 31 Suppl: S192-S197.

\section{Acknowledgements}

Special thanks to Drs. Hazlina Abdul Ghani and Nur Hafizah B Kamar Affendi for their contribution of the clinical cases and revision of the manuscript. 